\title{
A Two-Stage PV Accommodation Optimization in Jinzhai County, Anhui Province with Hydropower as Stand-By Unit
}

\author{
Tianyi $\mathrm{LIU}^{1 *}$, Hai BAO${ }^{1}$ \\ ${ }^{1}$ School of Electrical and Electronic Engineering, North China Electric Power University, Beijing, 102206, China
}

\begin{abstract}
In respond to the national "Photovoltaic Poverty Alleviation" and renewable energy accommodation policy, this paper proposes a two-stage PV accommodation optimization strategy based on improved PSO, PV forecast, and hydropower dispatch to tackle with the instability caused by distributed PV, since Jinzhai County, Anhui Province has both sufficient hydropower and photovoltaic. In the first stage, the hydropower reserve capacity of each period of the next day is optimized according to the PV forecast. In the second stage, real-time online optimization is carried out using the operation data to determine the amount of power generated by each PV source during each period. Finally, the optimization strategy is verified by simulations using grid operation data in Jinzhai, and the comparison is made with the thermal power standby unit. The results show that the hydropower units which has higher climbing rate can immensely increase the photovoltaic consumption, reduce the power loss and enhance the voltage stability of the network.
\end{abstract}

\section{Introduction}

On May 16, 2019, the National Energy Administration of China and the National Development and Reform Commission of China jointly issued the "Establishment and Improvement of Renewable Energy Power Consumption Guarantee Mechanism"[1], which strictly set the renewable energy consumption responsibility weight for the provinces and municipalities, and provided a strong guarantee for the renewable energy consumption. Photovoltaic (PV) has been widely developed in recent years due to its rich resources, environment-friendly and geographical advantages. Even though the access of distributed PV power can alleviate the pressure of power supply, the randomness and intermittence of solar energy make the power output fluctuate greatly. Therefore, as an uncontrollable power source, PV raises important issues such as the impact on the safety and reliable operation of power system as its penetration grows[2].

Many scholars have conducted researches on renewable energy accommodation from different aspects. Policies including fixed price subsidy, quota system, mandatory purchase system, and green certificate are prerequisites[3]. Introducing demand response can make the load relatively controllable[4-5]; Joint consumption such as wind-PV, wind-PV-tide, and wind-EV plays an important role in renewable energy consumption. Transmission between provinces is a characteristic is China[7]; The energy storage system has dual characteristics of source and load, which can quickly change the instantaneous power of the system[8].
However, there is a scarcity in the literature studying on hydropower reserve's influence on PV accommodation.

Considering the distribution of renewable energy in Jinzhai, Anhui, it is necessary to study the joint consumption of hydropower and photovoltaic. On the one hand, Jinzhai, located in the western border of Anhui, is the largest county in Anhui Province, which has excellent potential for the development of photovoltaic industry. The government has made a series of efforts to help the families below poverty line which include issuing "photovoltaic poverty alleviation" policy. Over the years, thousands of rooftop PV sources have been installed in response to "photovoltaic poverty alleviation" policy, which gradually makes the system reach its limit to accommodate more PV. On the other hand, Anhui Province is also rich in hydropower resources. In the early years, several water conservancy projects were built, including Meishan, Foziling and Chencun Hydropower Stations. Entering the 21st century, many large pumped storage power stations with a capacity of more than one million kilowatts are under construction, many of which are built as supporting facilities of distributed photovoltaic. It is of great significance to optimize the operation strategies.

This paper proposes a two-stage PV accommodation optimization strategy using hydropower as stand-by units since hydropower has high climbing rate. In the first stage, the hydropower reserve capacity of each period of the next day is optimized according to the PV forecast. In the second stage, real-time online optimization is carried out using the operation data to determine the amount of power generated by each distributed PV source during each period. Finally, the optimization strategy is verified

${ }^{*}$ Corresponding author's e-mail: 1182201060@ncepu.edu.cn 
by simulations using operation data in Jinzhai, and the comparison is made with the thermal power stand-by unit.

\section{Methods and Materials}

\subsection{Model analysis}

The reasons to use a two-stage optimization are that the reserve capacity need to be planned at least one day in advance and there is a deviation between PV forecast and the actual Distributed Generator(DG) output so real time optimization is needed. There should be enough hydro or thermal reserve capacity to stabilize the system when PV fluctuates. Since hydropower usually has higher climbing rate than thermal power, less reserve capacity will be needed if hydropower unit is used as stand-by unit rather than thermal power unit. When there is more PV power generated by DGs than load can consume, the distribution network will send energy back to the grid, so the voltages will be higher than 1(p.u.). If the PV DGs generate too much power, over voltage may occur.
This paper uses an improved Particle Swarm Optimization(PSO) to solve the model. The flow chart of PSO is shown in figure 1 . The variables to be solved as particles in the first-stage optimization are capacities of each stand-by unit. However, in order to running power flow, PV output of each DG has to be solved at the same time, which extends the dimension of variables to nearly two times. In the second-stage optimization, only PV output of each DG are variables to be solved as particles.

\subsection{Objective function}

To minimize reserve capacity:

$$
\min f_{1}=P_{\text {hyre }}+P_{\text {thre }}
$$

where $P_{\text {thre }}$ is total reserve capacity of thermal power and $P_{\text {hyre }}$ is total reserve capacity of hydropower.

To maximum PV consumption:

$$
\min f_{2}=-\sum_{j=1}^{N_{P V}} P_{P V j}
$$

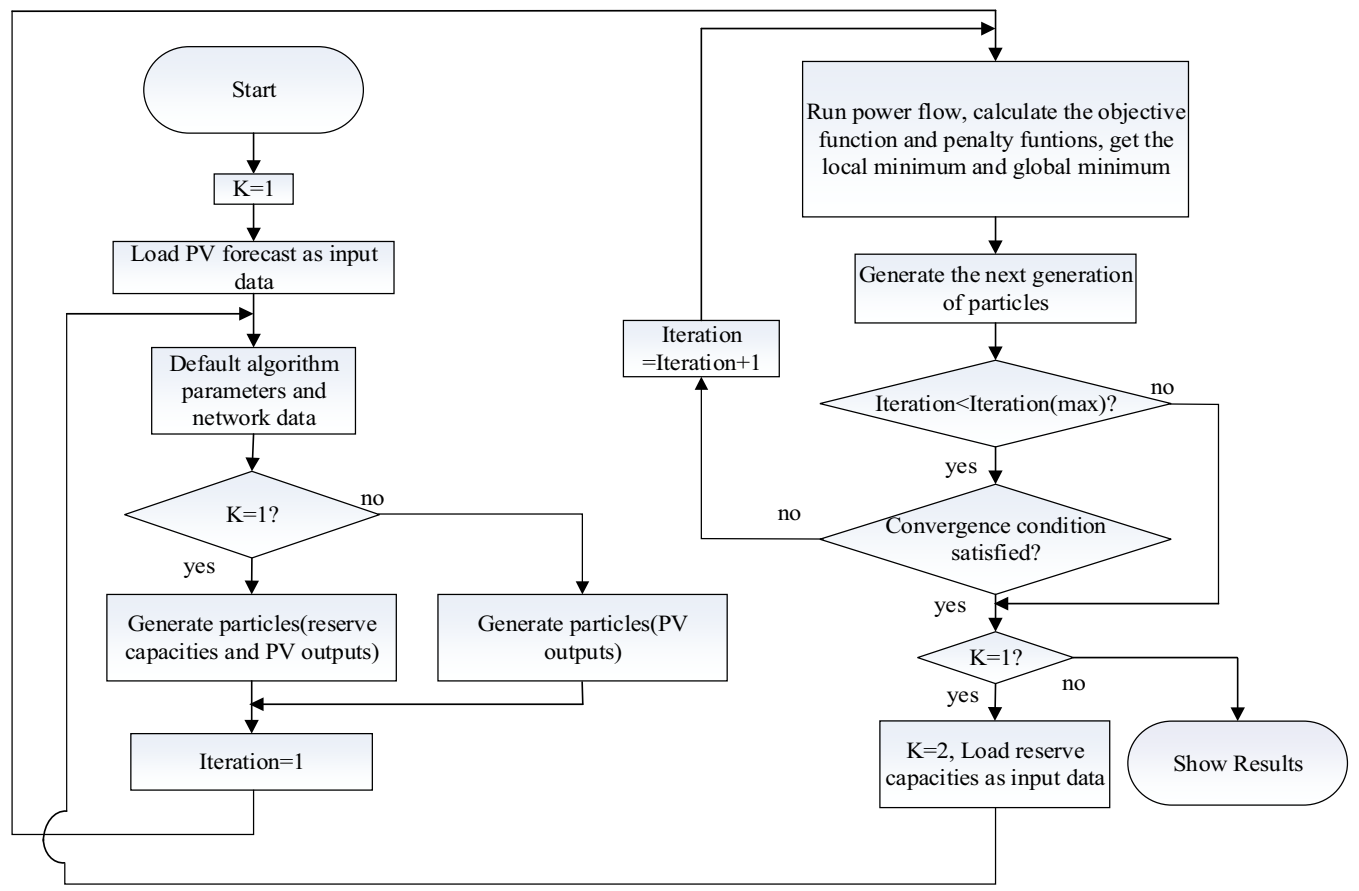

Figure 1. Flow chart of two-stage optimization

where $N_{P V}$ is the total number of PV sources and $P_{P V j}$ is the output power of jth PV source.

To minimize power loss:

$$
\min f_{3}=P_{\text {loss }}
$$

The objective function of the first-stage optimization is:

$$
\min F=r_{1} f_{1}+r_{2} f_{3}
$$

where $r_{1}$ and $r_{2}$ are weight coefficients.

The objective function of the second-stage optimization is:

$$
\min F=f_{2}+f_{3}
$$

\subsection{Constraints}

Power flow equation:

$$
\begin{gathered}
P_{G i}-P_{L i}=U_{i} \sum_{j=1}^{N} U_{j}\left(G_{i j} \cos \delta_{i j}+B_{i j} \sin \delta_{i j}\right) \\
Q_{G i}-Q_{L i}=U_{i} \sum_{j=1}^{N} U_{j}\left(G_{i j} \sin \delta_{i j}-B_{i j} \cos \delta_{i j}\right)
\end{gathered}
$$


where $P_{G i}, Q_{G i}, P_{L i}$ and $Q_{L i}$ are active/reactive source power and active/reactive load power.

Climbing rate of thermal power unit:

$$
-P_{\text {jown }}<P_{j, t+1}-P_{j, t}<P_{j u p}
$$

where $P_{j, t}$ is the output power of thermal power unit $\mathrm{j}$ at time t, $P_{j u p}$ and $P_{\text {jdown }}$ are up and down climbing rate of hydropower unit $\mathrm{j}$, both of which are $20 \%$ /min in this study.

Climbing rate of hydropower unit:

$$
-P_{\text {hyjown }}<P_{j, t+1}-P_{j, t}<P_{\text {hyjup }}
$$

where $P_{h y j, t}$ is the output power of hydropower unit j at time t, $P_{\text {hyjup }}$ and $P_{\text {hyjdown }}$ are up and down climbing rate of hydropower unit $\mathrm{j}$, both of which are $50 \% / \mathrm{min}$ in this study.

Voltage limits:

$$
U_{\min }<U_{i}<U_{\max }
$$

where $U_{\min }$ and $U_{\text {max }}$ are upper and lower limits of voltage at node $\mathrm{i}$ and $U_{i}$ is voltage at node $\mathrm{i}$.

Thermal unit limits:

$$
P_{j \min }<P_{j, t}<P_{j \max }
$$

where $P_{j \max }$ and $P_{j \min }$ are upper and lower power limits of thermal power unit $\mathrm{j}$.

Hydropower unit limits:

$$
P_{h y j \min }<P_{h y j, t}<P_{h y j \max }
$$

where $P_{h y j \max }$ and $P_{h y j \min }$ are upper and lower power limits of hydropower unit $\mathrm{j}$.

Transmission line capacity:

$$
P_{i j} \leq P_{i j}^{\max }
$$

where $P_{i j}$ is the power on transmission line $\mathrm{i}-\mathrm{j}$, and $P_{i j}^{\max }$ is maximum power on transmission line $\mathrm{i}-\mathrm{j}$.

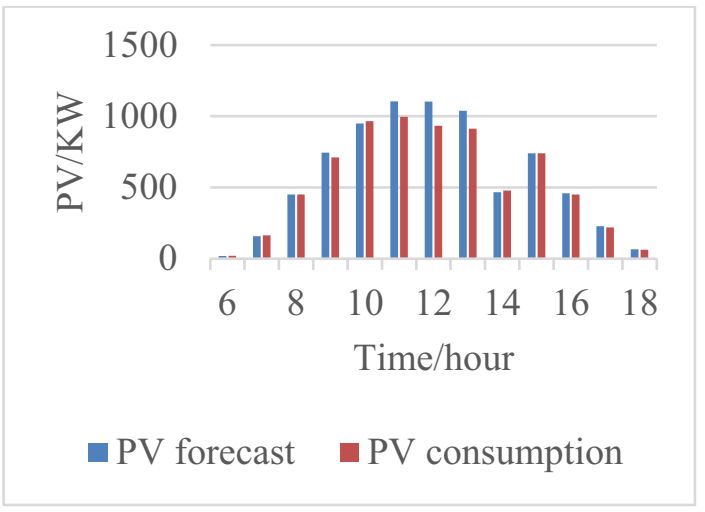

Figure 3. PV forecast and PV consumption

\subsection{Reserve capacity and PV consumption}

In the first stage, reserve capacity is optimized according to PV forecast (figure 3), as shown in figure 4.
Safety margin:

$$
P_{b c, t}>P_{b c \min , t}
$$

where $P_{b c, t}$ is total reserve capacity at time t, and $P_{b c \text { min, } t}$ is minimum reserve capacity at time $\mathrm{t}$.

Penalty functions are used to add constrains to objective functions.

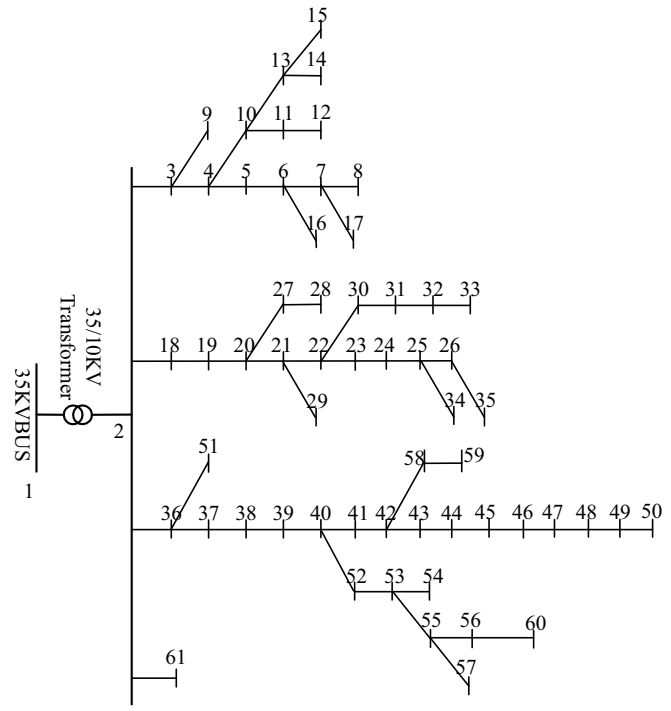

Figure 2. A distribution network in Jinzhai

\section{Simulations and Results}

\subsection{Distribution network}

The simulation network used in this study is shown in figure 2. It's a 61 nodes network in Jinzhai County. There is a hydropower plant at node 61 named Changjianghe Hydropower Plant, the capacity of which is much bigger than the load and the PV output in the network.

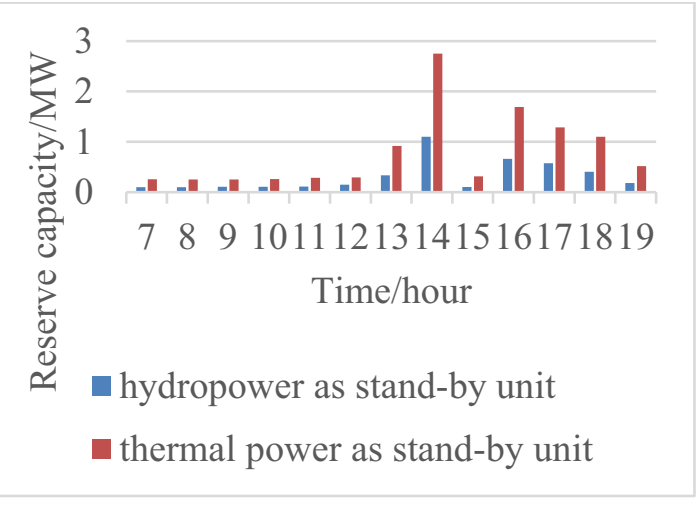

Figure 4. Reserve capacity with different kinds of standby unit

Comparisons are made between hydropower stand-by unit and thermal power stand-by unit. Total PV output declines from $1038.65 \mathrm{KW}$ to $466.46 \mathrm{KW}$ in a minute during $13: 00$ to $14: 00$ period. In order to filling in the 
power gap, $1099.97 \mathrm{KW}$ hydropower reserve or $2749.92 \mathrm{KW}$ thermal power reserve is needed. Figure 4 also indicates that when using hydropower, which has higher climbing rate, as stand-by unit, only around $44 \%$

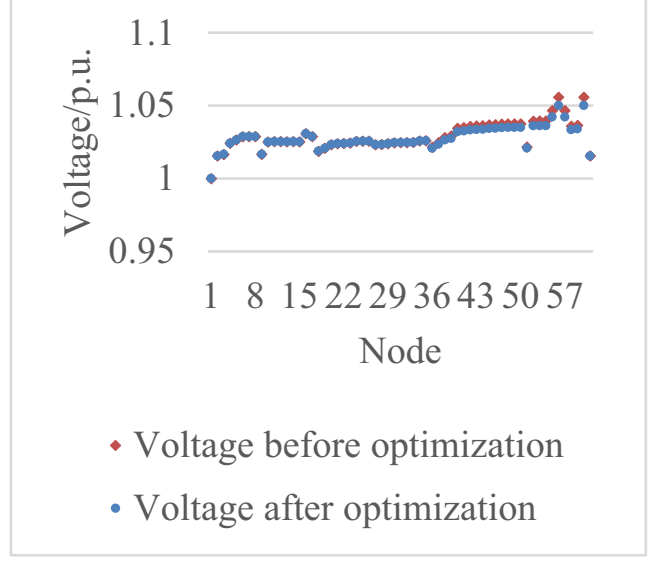

Figure 5. Voltage at each node before and after the optimization

\subsection{Voltage control}

During a light load, with total PV output being much more than the load, the distribution network sends power back to the grid, which causes over voltage(higher than 1.05 p.u.) at terminal nodes on some long transmission lines, as shown in figure 5 . The voltage after optimization is also shown in figure 5, within the acceptable range. The PV output of some DGs near the terminal of the transmission lines can not be fully consumed such as node 56,57 and 60 , as shown in figure 6.

\section{Conclusions}

In respond to the national "Photovoltaic Poverty Alleviation" and renewable energy accommodation policy in China, this paper proposes a two-stage optimization to maximum PV accommodation in Jinzhai County, Anhui Province. Our study has found out that by planning reserve capacity in advance, there is no need to maintain high reserve capacity all day long. When using hydropower which has higher climbing rate as stand-by unit only around $44 \%$ reserve capacity is needed comparing with using thermal power stand-by unit. In addition, during the iterations, the voltage need to be controlled by a penalty function so it won't exceed upper limit when the distribution network is sending power back to the gird.

\section{References}

1. The National Energy Administration of China, the National Development and Reform Commission of China. (2019) Establishment and Improvement of Renewable Energy Power Consumption Guarantee Mechanism. http://zfxxgk.nea.gov.cn/auto87/201905/t20190515 3662.htm. (in Chinese) reserve capacity is needed comparing with thermal power stand-by unit. In the second stage, PV consumption is optimized with real time load data, as shown in figure 3.

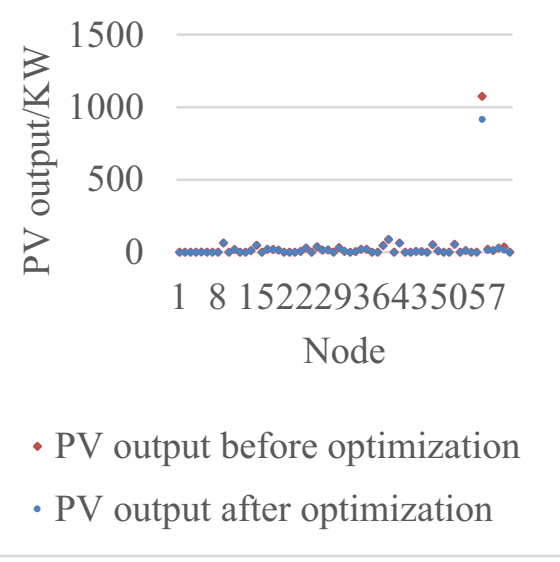

Figure 6. PV consumption before and after the optimization

2. Shayani, R.A. (2011) Photovoltaic generation penetration limits in radial distribution systems. IEEE Transactions on Power Systems, 26(3): 1625 1631.

3. Tian, W., Shan, M., Lu, R., Xu, Y. and Ding, T. (2019) Stochastic Unit Commitment to Accommodate Renewable Energy with Renewable Portfolio Standard. In: 2019 IEEE Sustainable Power and Energy Conference. Beijing. pp. 14011405 .

4. Jonghe, C.D., Hobbs, B.F., Belmans, R. (2012) Optimal Generation Mix With Short-Term Demand Response and Wind Penetration. Power Systems IEEE Transactions, 27(2): 830-839.

5. John, D.V., Beno, M.M. (2014) Battery Energy Storage Station Based Smoothing Control of Wind and Photovoltaic Power Generation Fluctuations Using SOC Control Strategy. Asian Journal of Electrical Sciences, 3(1):18-22.

6. Mohammed, O.H., Amirat, Y., Benbouzid, M., Haddad, S. and Feld, G. (2016) Optimal sizing and energy management of hybrid wind/tidal/PV power generation system for remote areas: Application to the Ouessant French Island. In: IECON 2016 - 42nd Annual Conference of the IEEE Industrial Electronics Society. Florence. pp. 4205-4210.

7. Gao, C., Niu D. (2017) Accommodating Capability Analysis and Comprehensive Assessment Method of Large-Scale New Energy Areas Interconnected. Electric Power, 50(07): 56-63. (in Chinese)

8. Song, Y., Tan Z., Li, H. (2014) An Optimization Model Combining Generation Side and Energy Storage System With Demand Side to Promote Accommodation of Wind Power. Power System Technology, 2014(3): 610-615. (in Chinese) 